\title{
LA FUNCION DEL BOSTEZO EN LA COMUNICACION SOCIAL DE UN GRUPO DE BABUINOS
}

\author{
José María Naranjo Navarro \\ Universidad Autónoma de Madrid.
}

\section{INTRODUCCION}

El bostezo es una expresión facial que en los babuinos puede variar en intensidad según la posición de los elementos faciales. La abertura de la boca puede ir desde aproximadamente $45^{\circ}$, con los caninos expuestos ligeramente por una incompleta retracción de los labios, hasta una abertura máxima de más de $90^{\circ}$, aparentemente aumentada por una exposición de todos los dientes y la mayor parte de las encías, como consecuencia de una retracción completa de los labios. En este último caso, la expresión va acompañada de retracción de las cejas y cuero cabelludo, y aplastamiento de las orejas contra la cabeza.

Sin embargo el bostezo no es considerado como tal expresión facial por algunos autores (Van Hooff, 1962, 1969; Bolwig, 1964), mientras que para otros (Redican, 1975; Pellatt, 1980; Naranjo, 1985a) cumple una importante función en la comunicación social de los babuinos y de otros primates.

Hall (1967) distingue entre el bostezo dirigido y el no dirigido; Deputte (1978) revela dos categorías de bostezo, el de inactividad y el de emotividad. Ambas distinciones parecen coincidir con la división realizada por Redican (1975) en bostezo fisiológico, producido por un exceso de anhidrido carbónico o un déficit de oxígeno en el sistema arterial del cerebro, y bostezo de tensión, que es considerado como una exhibición facial.

Kummer (1968) indica que el bostezo puede considerarse como una amenaza de baja intensidad, por lo que pretendemos observar la relación que tiene con otras expresiones de amenaza como son "boca tensa" y "mirada fija y boca abierta" que en algunos trabajos han sido utilizadas como índices para establecer rangos de dominancia en primates (Richards, 1974; Naranjo, 1985b).

\section{Método y procedimiento}

Se observó un grupo de babuinos, Paio hamadryas, Papio cynocephalus e híbridos de ambas especies en el Parque Zoológico de la Casa de Campo de Madrid a lo largo de cuatro meses.

Realizamos un muestreo focal (Altmann, 1974) de forma que cada inviduo del grupo, formado por ocho machos (cuatro adultos y dos subadultos) y quince hembras (once adultas y cuatro subadultas) fue observado en veinticinco períodos de quince minutos cada uno de ellos, registrando la conducta mediante la utilización de lápiz y papel. 
Los veintitres animales fueron ordenados jerárquicamente según la frecuencia de emisión y la frecuencia de recepción de cada una de las tres expresiones faciales consideradas, "boca tensa" (EBT), "mirada fija y boca abierta" (EFA) y "bostezo" (EBO). A continuación aplicamos el coeficiente de correlación de Spearman (rs) para obtener las correlaciones entre los distintos rangos.

\section{Resultados}

Tabla 1. Correlaciones entre las tres expresiones consideradas, según $r_{\mathrm{S}}$ de Spearman, a partir de los rangos obtenidos conforme a la frecuencia de emisión o recepción de dichas expresiones.

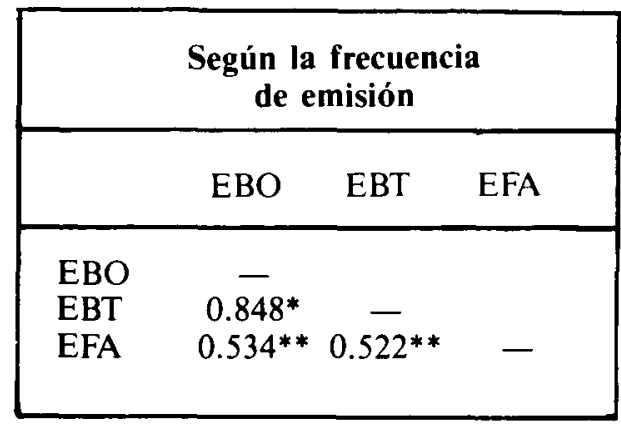

**Correlación significativa a un nivel de 0.01 .

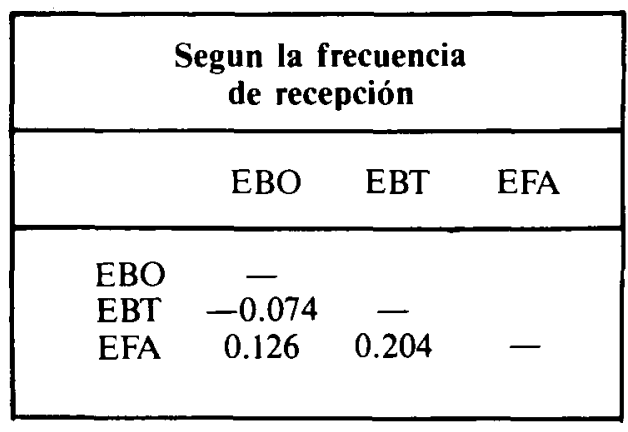

\section{Discusión}

Las tres expresiones tienen correlaciones positivas entre sí, muy altas, cuando consideramos la frecuencia de emisión, lo que prueba que son realizadas por animales que ocupan posiciones similares en un rango de dominancia. Las expresiones de amenaza son realizadas con mayor frecuencia por individuos dominantes dirigidas a individuos subordinados (Richards, 1974; Redican, 1975) por lo que podemos confirmar la consideración de Kummer (1968) para el cual el bostezo funciona como una amenaza de baja intensidad.

Por otra parte, atendiendo a la frecuencia de recepción, no encontramos correlaciones significativas entre los diferentes rangos. La explicación puede residir en la baja frecuencia con la que los animales dominantes reciben expresiones de amenaza (EBT y EFA), recibiendo en cambio "bostezo" en bastantes ocasiones. De hecho, los seis primeros animales del rango de dominancia (los cuatro machos adultos y dos subadultos) fueron receptores en conjunto del $51 \%$ de los bostezos y unicamente del $11 \%$ de las otras dos amenazas.

Ya Hall (1967) y Pellatt (1980) señalan que el bostezo ocurre casi exclusivamente en las interacciones entre machos adultos, lo cual puede explicar que los individuos dominantes sean al tiempo los que con más frecuencia realizan y también los que con más frecuencia reciben la mencionada expresión.

Por tanto el bostezo, al igual que otras expresiones de amenaza, puede ser utilizado para resolver una situación conflictiva entre dos individuos, siendo su función comunicativa de un alto valor adaptativo, especialmente para aquellos animales que viven en grupos sociales, porque pueden resolver sus conflictos sin recurrir a la agresión física. 


\section{REFERENCIAS}

Altmann, J.: Observational study of behavior: Sampling methods. Behaviour, 1974, 49, 227-265.

Bolwig, N.: Facil expression in primates with remarks on a parallel development in certain carnivores. Behaviour, 1964, 22, 167-193.

Deputte, B.L.: Etude du bâillement chez deux espèces de Cercopithecidae, Cercocebus albigena Gray et Macaca fascicularis Raffles: Recherche de facteurs de causalité et de fonction. Mise en évidence de facteurs socio-bioénergétiques. Thèse de Doctorat de 3eme cycle, Université de Rennes, 1978.

Hall, K.L.R.: Social interactions of the adult male and females of patas monkeys group. En S.A. Altmann (ed.): Social Communication among primates; pp. 261-280. Chicago, University of Chicago Press, 1967.

Kummer, H.: Social organization of hamadryas baboons. Bibl. Primatol., 6, Basel, Karger, 1968.

Naranjo, J.M.: Expresión facial y organización social en una colonia de babuino cutivos (Papio hamadryas, Papio cynocephalus y sus hibridos). Tesis doctoral no publicada. Universidad Autónoma de Madrid, 1985a.

Naranjo, J.M.: Differences between two threat expresssions' in their value as a dominance index in a baboon colony. Am. J. Primatol., 1985b, 8, 354-355.

Pellat, A.: Facial expressions of Papio Ursinus and some other higher primates. S. Afr. J. Sci., 1980, 76, 413-418.

Redican, W.: Facial expressions in nonhuman primates. En L.A. Rosenblum (ed.): Primate Behavior. vol. 4. Developments in Field and Laboratory Research, pp. 103-194, New York, Academic Press, 1975.

Richards, S.M.: The concept of dominance and methods of assessment. Anim. Behav. 1974, 22, 914-930.

Van Hooff, J.A.R.A.M.: Facial expressions in higher primates. Symp. Zool. Soc. Lond., $1962,8,97-125$.

Van Hooff, J.A.R.A.M.: The facial dysplays of the catarrhine monkeys and apes. En D. Morris (ed.): Primate Ethology, pp. 9-88, Garden City, Anchor Doubleday, 1969. 